\title{
Austeridade fiscal e seus impactos sobre o gasto público em saúde e educação no Brasil
}

\author{
Isabella P. de C. Abreu*, Pedro L. Rossi.
}

\section{Resumo}

O projeto aqui proposto tem como objetivo central analisar os impactos da política fiscal brasileira recente sobre os gastos públicos em saúde e educação, áreas com acesso garantido como direito pela Constituição Federal de 1988, definidos em seu Art. 6․ No Brasil, as políticas de austeridade assumiram protagonismo a partir de 2015 como um plano de ajuste de curto prazo da economia brasileira, após um processo de desaceleração econômica e deterioração das contas públicas. A partir de 2016, porém, com a Emenda Constitucional 95, os princípios da austeridade passam a nortear o setor público de forma estrutural. Em vez de um ajuste temporário das contas públicas, a nova regra fiscal impõe uma redução do tamanho do Estado para os próximos vinte anos. Trata-se de outro projeto de país, diferente daquele almejado pela Constituição de 1988. Nesse contexto, a pergunta pertinente ao estudo é se esse novo contexto fiscal é compatível com a garantia dos direitos constitucionais de acesso à saúde e educação.

\section{Palavras-chave:}

austeridade fiscal, educação, saúde

\section{Introdução}

Nas últimas décadas, o Brasil viveu um período de relativo progresso social, com melhoras no acesso a direitos sociais e redução substantiva da pobreza. Entretanto, desde 2015, o Brasil enfrenta uma das piores crises de sua história, cenário no qual a defesa da austeridade tem se fortalecido, tomando o papel de protagonista.

Presente nas políticas econômicas e nas reformas estruturais, a austeridade representa um encolhimento do Estado, cujos gastos passam a ser contidos visando uma recuperação econômica. Todavia, por diversos fatores a serem tratados no presente trabalho, tem-se que tal posicionamento é contraproducente, impactando negativamente o crescimento econômico e ameaçando as recentes conquistas econômicas e sociais.

Tendo como ponto de inflexão estrutural a promulgação da Emenda Constitucional 95, que estabelece um teto para o gasto primário do Governo Federal para os próximos 20 anos, o regime fiscal no Brasil assume uma nova forma. No entanto, com o crescimento real das despesas públicas sendo nulo, os diversos papéis desempenhados pela política fiscal tornam-se cada vez mais ineficientes, como as dimensões redistributiva, estabilizadora e de provisão de bens e serviços públicos. ${ }^{1}$

Dessa forma, o presente trabalho tem como objetivo: $1^{\circ}$ ) caracterizar o que se entende por austeridade fiscal, seus impactos macroeconômicos e os motivos que levam à sua adoção e $2^{\circ}$ ) avaliar os impactos da austeridade fiscal no Brasil no gasto público com saúde e educação, garantidos como direito pela Constituição Federal de 1988, definidos em seu Art. 6․․

\section{Resultados e Discussão}

$\mathrm{Na}$ prática, o trabalho realizado consistiu na revisão de bibliografia acadêmica e de documentos oficiais pertinentes à discussão, assim como na análise das estatísticas concernentes desde ao orçamento público voltado à saúde e educação, até indicadores relacionados ao que fora exposto.

Dessa forma, não apenas pelos impactos já observados, mas inclusive com base nas projeções que tomam como princípio o estabelecimento do teto dos gastos públicos, observa-se que a austeridade resulta em significativas perdas para investimentos chave em saúde e educação. No entanto, indo para além dos aspectos econômicos, o trabalho se atenta aos impactos sociais relacionados ao corte das despesas, visando uma abordagem não apenas quantitativa, mas também qualitativa.

\section{Conclusões}

A partir do estudo realizado no presente trabalho, vemos que a nova política fiscal propõe um Brasil muito diferente do almejado pela CF88, uma vez que estabelece a redução relativa dos gastos sociais e busca um encolhimento da atuação Estatal. Por consequência, aquilo que é tido como direito passa a ser visto como mera mercadoria e, não somente a proteção da parcela da população que se encontra em uma condição vulnerável deixa de ser prioridade, como também tais indivíduos são excluídos do sistema². Além disso, vemos que os cortes orçamentários pró-cíclicos, que afetam principalmente os direitos humanos como saúde e educação, apenas contribuem para a deterioração da situação de um país cujo sistema tributário já apresenta uma baixa capacidade redistributiva, penalizando os mais pobres e reforçando a desigualdade social. Em suma, temos 0 desmonte do Estado Brasileiro e 0 sucateamento dos serviços públicos, o que acarreta uma série de impactos e retrocesso sociais ${ }^{3}$.

\section{Agradecimentos}

Agradeço ao programa de Programas de Iniciação Científica e Tecnológica da UNICAMP (PIBIC) e ao CNPq, que financiou este projeto.

\footnotetext{
ROSSI, Pedro; DWECK, Esther; OLIVEIRA, Ana Luíza M. de (org). Economia para poucos: impactos sociais da austeridade e alternativas para o Brasil. São Paulo: Autonomia Literária, 2018.

2 PLATAFORMA DESCHA, 2017. "Relatório sobre o impacto da política econômica de austeridade nos direitos humanos."

3 ROSSI, Pedro; DWECK, Esther. (2016). Impactos do Novo Regime Fiscal na Saúde e Educação In: Cadernos de Saúde Pública, 32(12).

et al. (2018) Child morbidity and mortality associated with alternative policy responses to the economic crisis in Brazil: A nationwide microsimulation study. PLOS Medicine 15(5): e1002570.
} 